\title{
Application of Stochastic Processes to Almost Ideal Demand System (AIDS) Models
}

\author{
K.L. Muruganantha Prasad, V. Geetha, R. Subramoniam
}

\section{INTRODUCTION}

The world's worst recorded food disaster happened in 1943, in British-ruled India, and is known as the Bengal Famine. It is estimated that four million people died of hunger that year alone in eastern India (Ganguly, 2002). The reason for the severity of the famine was the hoarding of grains by Indian food traders who would sell goods at high prices in order to obtain large profits. When the British left India in 1947, the number one concern was to ensure that such a famine never happened again. It led to legislative measures that prohibit any person from monopolizing the food markets, and was a major contributor to the green revolution.

Although the green revolution did not start until some time later (1965-1978), many ideas and concepts were being generated in this post-famine period to alleviate the food problem that India was facing. In the early stages of planning, the general idea had been to expand cropland and simply plant more acres in order to produce more. The efforts to expand the farmland base did not ease the problem of hunger entirely; people were still dying from starvation (Ganguly, 2002). The Government of India (GOI) turned its attention to increasing production levels in order to become self-sufficient in food production.

One of the primary features that the green revolution brought about was cropping intensity, but the problem with this approach was the lack of water to produce multiple crops. The GOI solved the problem by implementing a plan that would allow for dams to be built that would capture the runoff water from the rains (Ganguly 2002). By building these dams, the GOI had a secondary water source that would allow for two or three growing seasons in the same year.

The second benefit of the green revolution was the introduction of high yielding varieties (HYV). In 1960, the total area under the HYV was only 1.9 million hectares; it increased to almost 15.4 million hectares by $1970,43.1$ million hectares by 1980, and had grown to 63.0 million hectares by 1990 (Worden and Heitzman, 1999). With the increase in area under HYV, the amount of food that was being produced multiplied greatly, with the greatest increases coming from wheat and rice production. By 1980, almost $75 \%$ of the total cropped area under wheat was sown

Revised Manuscript Received July 10, 2019.

K.L. Muruganantha Prasad, Department of Mathematics, H.H. The Rajahs College, Pudhukottai, Tamilnadu, India.

V. Geetha, Research Scholar, H.H. The Rajahs College, Pudhukottai, Tamilnadu, India.

R. Subramoniam, Department of Mathematics, Lekshmipuram College of Arts and Science, Neyyoor, Tamilnadu, India. with HYV, and almost $45 \%$ of total rice area was under HYV (Worden and Heitzman, 1999).

The adoption of new crop production technologies resulted in a significant increase in Indian food production, which has grown at an annual rate of 2.5 percent over the last four decades (Mohanty and Peterson, 2001). Currently, India is one of the leading producers of wheat, rice, and coarse grains and is largely self-sufficient in grain production with occasional imports and exports in years of shortages or surpluses respectively. Today, India ranks second in the world both in wheat and rice production with 68 and 89 million metric tonns (mmt) produced annually (USDA, 2001). Currently, the agricultural sector accounts for about 25 percent of the gross domestic product, and engages almost 67 percent of the labor force (CIA, 2002).

\section{THE CONCEPT OF DEMAND FUNCTION}

Measuring consumption is quite a difficult task. Consumption includes several components: all the individual expenditure on goods and services, a value for consumption that does not go through the market (home production, transfer in kind, etc.) and a value for durable goods possessed. For the latter some sort of consumption flow needs to be imputed. There is an important distinction to make between consumption and expenditure the former includes the value of service flows from durable items and assets (such as home, vehicles, washing machine, computers, etc.) whereas the latter includes current expenses on the purchase of these items. Theoretically, consumption is preferable to expenditure as it better reflects material resources, although in practice estimating the value of service flows involves crucial assumptions(such as definition of durable good, depreciation rate of different items, etc.). The methods adopted to construct consumption measures significantly vary among countries and over time. Most of the choices involved with the measurement of consumption are usually driven by data availability or by comparability over time within a country. There exist, however, good practice techniques and guidelines which one could look at when trying to construct an accurate measure of consumption. Total household consumption expenditure should comprise: food consumption, non food consumption, education expenditure and housing expenditure. In revising the method adopted by the Bolivian National Institute of Statistics (INE), it emerged, however, that computation of the total consumption expenditure was not clear and consistent.

\section{Published By:}

Blue Eyes Intelligence Engineering

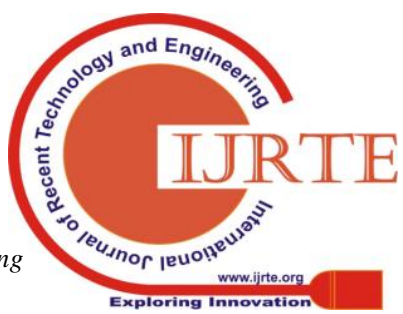


However, from 2005 onwards INE includes in the consumption aggregate only the current expenditure thus excluding the value of service flows of durables. Moreover, in computing current expenditure, durable goods and expenditures made in house repair and construction that are above a certain threshold are excluded because they are regarded as investment rather than consumption. As a result, a lack of consistency in the definition and construction of consumption aggregates provided by the INE is apparent and that simply prevents one from comparing those figures over time. Aware of that, the only feasible option for conducting sound research using consumption data is devoting intense effort to create original, consistent, accurate consumption estimates. This task, although very time consuming, represents a notable and original contribution of the present study to the literature. To estimate consumption figures the following components have been aggregated: Food consumption inside the household(food purchases, self-produced food, food from other sources-such as gifts, transfers in kind)

Food consumed outside the household (breakfast, drinks, lunch/dinner, snacks,..)

Non-food consumption (aggregate of about 40 categories related to current housing costs, domestic fuel and power, tobacco products, clothing and footwear, medical care and health expenses, transport, recreation, personal care, miscellaneous goods and services.

Education expenditure (tuition fees, transport, books and copies, uniform, etc.)

Housing expenditure (actual rent or rental equivalence value, expenses- gas, water, electricity, telephone-house repair-decoration)

The computation has been done at the (per capita) household level. When the expenditure was reported at the individual level, the household aggregate has been computed and the per capita mean has then been obtained dividing the household figure by the household size. As respondents are allowed for some modules to answer in Rupees, all the values in Rupees have been converted into real inside the house such as beds, TV, microwave oven, etc. Information on the method used to impute such values.

In the case of consumption, the willingness to buy a commodity, that is the demand for that, depends on the factors such as

1. The income of the consumer

2. The price of that commodity

3. Prices of other goods and services on which the consumer spends his income.

4. Tastes and preferences of the consumer, size of the family, social customs, expectations and advertisements. etc.

In the case of a farm or firm, the input demand for commodity depends on the factors like:

1. The total outlay or expenditure of the firm

2. The price of that commodity

3. Prices of other substitutes and complementary inputs

4. The nature of technology, etc.

Since the study is on consumer demand, we shall restrict to it only.
A consumer demand function for a commodity specifies the relationship between quantity of the commodity that the consumer is willing to buy and the demand factors. In mathematical form, the demand function for a commodity is express as.

$$
Q_{X}=D_{X}\left[P_{X^{\prime}} P_{s^{\prime}} P_{c^{\prime}}, Y, T\right]
$$

where $Q_{x}$ is the quantity of the commodity $X$ demanded, $P_{x}$ is the price of the commodity, $\mathrm{P}_{\mathrm{s}}$ denotes the price of other commodity which can be substituted for $\mathrm{X}, \mathrm{P}_{\mathrm{c}}$ is the price of the commodity which is the complement of commodity $\mathrm{X}, \mathrm{Y}$ is the income of the consumer and $\mathrm{T}$ represents other demand factors such as tastes, preferences, social customs, etc, $D_{x}$ indicates the functional form of the relationship. There may be more than one substitute and/or complementary goods for commodity $\mathrm{X}$, In this situation the specification of the demand function for commodity $\mathrm{X}$ can be expanded by including their prices. The demand function may be linear or non-linear. It is a common observation that for most of the commodities, the willingness to buy decreases as price of the commodity increases. The law of demand states that other things being equal, the quantity demanded of the commodity varies inversely with its price. However in the case of consumer demand, an increase (decrease) in income of the consumer increases (decreases) the demand for the commodity. These commodities are called normal goods. For certain commodities, after a certain level of income of the consumer, the quantity demanded starts decreasing with increase in income. These are called inferior goods. In the case of food items, a rise in income causes an increase in quantity demanded in the initial stage but after a certain level of the consumer's income, the quantity demanded become invariable with respect to the income. There is a simple generalization of the relationship between consumer goods and income for a consumer, which is known as Engel's law. According to this law, as income increases the portion of income spent on food declines and the portion spent on comforts and luxuries increases.

\section{ELASTICITY}

Elasticity in demand theory is used to measure the responsiveness of the quantity demanded of a commodity to the change in price or income. It is defined as the unit percentage change in a demand factor. In symbols

Elasticity $=\frac{(\Delta \mathrm{Q} / \mathrm{Q})}{(\Delta \mathrm{X} / \mathrm{X})}$

Where $\mathrm{Q}$ is the quantity demanded of a commodity when $\mathrm{X}$ is the price and $\frac{\mathrm{dQ}}{\mathrm{dX}} \cdot \frac{\mathrm{X}}{\mathrm{Q}}=\frac{\partial(\log \mathrm{Q})}{\partial(\log \mathrm{X})}$

is called the point elasticity since it gives the elasticity of demand at a point on the demand curve. 


\section{CONSUMER BEHAVIOUR}

A consumer at a time consumes one or more commodities. He gets satisfaction or derives utility by consuming the goods. The level of satisfaction or utility derived by him depends on quantities of the goods consumed. This is a basic consumer theory. According to this, we say that utility derived from consumption of a commodity depends exclusively on its quantity, other things being constant.

In symbols.

$$
U_{i}=F_{i}\left(q_{i}\right), \quad i=1,2 \ldots \ldots . n
$$

Where $U_{i}$ is the level of utility.

$q_{i}$ is the quantity of $i^{\text {th }}$ commodity

and $F_{i}$ denotes the shape of the relationship.

If there are $n$ commodities,

$\mathrm{U}=\mathrm{F}\left(\mathrm{q}_{1}, \mathrm{q}_{2} \ldots \ldots . \mathrm{q}_{\mathrm{n}}\right)$

This is called utility function.

The first partial derivatives of $U$, otherwise known as marginal utilities are interpreted as the change in total utility by consuming one more extra unit of a commodity keeping the levels of other commodity constant. There is a law of diminishing marginal utility, according to this "As quantity consumed of a commodity increases, the marginal utility of that commodity tends to decline"

$$
\text { i.e, } \frac{\partial^{2} U}{\partial q_{i}^{2}}<0
$$

A consumer at a time needs several goods and services for consumption. His income is limited. Now he wants to maximize his total utility by consuming all goods and services subject to the income constraint.

This can be formalized as

$\operatorname{Max} \mathrm{U}=\mathrm{F}\left(\mathrm{q}_{1}, \mathrm{q}_{2}, \ldots . \mathrm{q}_{\mathrm{n}}\right)$

Subject to

$\mathrm{y}=\mathrm{P}_{1} \mathrm{q}_{1}+\mathrm{P}_{2} \mathrm{q}_{2}+\ldots \ldots \ldots+\mathrm{P}_{\mathrm{n}} \mathrm{q}_{\mathrm{n}}$

Where $\mathrm{y}$ is the income, $\mathrm{P}_{1}, \mathrm{P}_{2} \ldots \mathrm{P}_{\mathrm{n}}$ are fixed prices for $\mathrm{q}_{1}, \mathrm{q}_{2}$ $\ldots . . \mathrm{q}_{\mathrm{n}}$ respectively.

This can be solved by the use of Lagrange function $\mathrm{L}=\mathrm{F}\left(\mathrm{q}_{1}, \mathrm{q}_{2} \ldots \mathrm{q}_{\mathrm{n}}\right)+\lambda\left[\mathrm{y}-\mathrm{P}_{1} \mathrm{q}_{1}-\mathrm{P}_{2} \mathrm{q}_{2}-\ldots . . \mathrm{P}_{\mathrm{n}} \mathrm{q}_{\mathrm{n}}\right]$

Equating the partial derivatives to zero,

$\mathrm{F}_{\mathrm{i}}=\lambda \mathrm{P}_{\mathrm{i}}$

Where

$$
\begin{aligned}
& \mathrm{F}_{\mathrm{i}}=\frac{\partial \mathrm{F}}{\partial \mathrm{q}_{\mathrm{i}}}, \mathrm{i}=1,2 \ldots \mathrm{n} \\
& \text { and } \mathrm{F}_{1}=\frac{F_{2}}{P_{2}}=\ldots=\frac{F_{n}}{P_{n}}=\lambda \\
& \frac{1}{P_{1}}=\frac{2}{P_{2}}=\ldots=\frac{n}{P_{n}}=\lambda \\
& \text { i.e., } \frac{M_{1}}{P_{1}}=\frac{M U_{2}}{P_{2}}=\ldots .=\frac{M U_{n}}{P_{n}}=M U \text { of money }(=\lambda) \\
& \text { Where } \quad M_{i}=\text { marginal utility of } U \text { w.r.to } q_{i} \\
& \text { i.e., } \frac{M U_{i}}{M U_{j}}=\frac{P_{i}}{P_{j}}
\end{aligned}
$$

i.e., The ratio of marginal utilities of two commodities must be equal to the ratio of their prices. This ratio is defined as the rate of substitution between these goods.

\section{DERIVATION OF DEMAND FUNCTION}

The set of $(n+1)$ equations in (1) for the $(n+1)$ unknowns is solvable. The solution will be in terms of known variables. Let it be

$$
\begin{array}{ll}
\mathrm{q}_{\mathrm{i}}=\phi_{\mathrm{i}}\left(\mathrm{P}_{1}, \mathrm{P}_{2}, \ldots \mathrm{P}_{\mathrm{n}}, \mathrm{y}\right), \quad \mathrm{i}=1,2 \ldots . \mathrm{n} \\
\lambda=\lambda^{0}\left(\mathrm{P}_{1}, \mathrm{P}_{2}, \ldots \mathrm{P}_{\mathrm{n}}, \mathrm{y}\right)
\end{array}
$$

Where $\phi_{\mathrm{I}}$ and $\lambda^{0}$ are functional relations. These are the demand functions for the different commodities. The above approach is called cardinal approach. The basic assumption for this was that utility could be measured through cardinal scale of measurement say in terms of 'utils'

\section{THE INDIFFERENCE CURVE ANALYSIS}

This is an alternative approach in which the emphasis is given on comparing different utility levels instead of measuring them through

some cardinal scale. The indifference curve approach is based on the following assumptions.

1. There is complete consistency in ordering of preference by the consumer.

2. The consumer's preferences are not conflicting with each other.

3. An individual's preferences are such that he prefers more to less.

4. The goods consumed by the consumer are substitutable.

5. All commodities in the consumption basket of the consumer are divisible.

6. Individuals are rational in decision-making.

Based on the above assumptions, the indifference curve technique compares the different levels of satisfaction or utility rather than measuring them.

The indifference curve is the locus of different combinations of two or more goods, which yield the same level of satisfaction or utility to the consumer. It is also called as iso-utility curve.

In the consumption process we are substituting one commodity for the other but maintaining a constant level of utility derived from them. This is called Rate of Commodity Substitution (RCS). If this is computed for very small changes it is called Marginal Rate of Commodity Substitution (MRCS). Hence RCS or MRCS is that amount of a commodity say $\mathrm{Q}_{2}$ to be given up per unit of another commodity say $\mathrm{Q}_{1}$ for consumption if the consumer remains on the same indifference curve.

A consumer's MRCS between two goods $\left(Q_{2}\right.$ and $\left.Q_{1}\right)$ for a constant level of utility will, in some way, depend on how many units of $\mathrm{Q}_{2}$ and $\mathrm{Q}_{1}$ he is currently consuming. That is the willingness to give up the commodity $\mathrm{Q}_{2}$ in favour of the other commodity $\mathrm{Q}_{1}$ directly relates to the quantity of $\mathrm{Q}_{2}$. This is the reason why the magnitude of MRCS of $\mathrm{Q}_{2}$ for $\mathrm{Q}_{1}$ declines as we decrease quantity of $\mathrm{Q}_{2}$ and increase quantity of $\mathrm{Q}_{1}$. 
The above phenomena can be well explained mathematically by the utility function.

Let $\mathrm{U}=\mathrm{F}\left(\mathrm{q}_{1}, \mathrm{q}_{2}\right)$ be the utility function for two commodities.

$$
\mathrm{dU}=\frac{\partial \mathrm{U}}{\partial \mathrm{q}_{1}} \mathrm{dq}_{1}+\frac{\partial \mathrm{U}}{\partial \mathrm{q}_{2}} \mathrm{dq}_{2}
$$

By definition of the indifference curve, $\mathrm{U}$ does not change on it.

$$
\begin{gathered}
\therefore \mathrm{dU}=0 \\
\therefore-\frac{\mathrm{dq}_{2}}{\mathrm{dq}_{1}}=\frac{\frac{\partial \mathrm{U}}{\partial \mathrm{q}_{1}}}{\frac{\partial \mathrm{U}}{\partial \mathrm{q}_{2}}}=\frac{\mathrm{F}_{1}}{\mathrm{~F}_{2}}
\end{gathered}
$$

The L.H.S. is the MRCS.

$$
\text { i.e, } \quad-\frac{\mathrm{dq}_{2}}{\mathrm{dq}_{1}}=\frac{\mathrm{MU}_{1}}{\mathrm{MU}_{2}}
$$

i.e., MRCS is equal to the ratio of marginal utilities of the two goods.

$$
\text { Since } \frac{\partial U}{\partial q_{1}} \geq 0 \text { and } \frac{\partial U}{\partial q_{2}} \geq 0 \text {, we must have } \frac{d q_{2}}{d q_{1}}
$$

to be negative. This is possible only if the in difference curve is negatively sloped.

The curvature of the indifference curve will give the degree of substitution between the goods represented by it. A consumer attains equilibrium when he spends his limited income on various goods and services. To study this through indifference curve, we need the information on his budget constraint.

A budget constraint is the locus of all combinations of two goods(or more) which can be purchased with fixed income at fixed prices.

Let $\mathrm{y}$ be the fixed income, $\mathrm{P}_{1}$ and $\mathrm{P}_{2}$, the fixed prices of two commodities. Then the budget constraint is $\mathrm{y}=\mathrm{P}_{1} \mathrm{q}_{1}+\mathrm{P}_{2} \mathrm{q}_{2}$

$$
\therefore \mathrm{q}_{2}=\frac{\mathrm{y}}{\mathrm{P}_{2}}-\frac{\mathrm{P}_{1}}{\mathrm{P}_{2}} \mathrm{q}_{1}
$$

i.e, it is a downward sloping curve.

$$
\text { If we maximize }
$$

Subject to the budget constraint, we get

$$
\frac{\mathrm{MU}_{1}}{\mathrm{MU}_{2}}=\frac{\mathrm{P}_{1}}{\mathrm{P}_{2}}
$$

From equation (2), we have

$$
-\frac{\mathrm{dq}_{2}}{\mathrm{dq_{1 }}}=\frac{\mathrm{MU}_{1}}{\mathrm{MU}_{2}}
$$

Combining the above two.

$$
\text { MRCS }=-\frac{d q_{2}}{d q_{1}}=\frac{M U_{1}}{M U_{2}}=\frac{P_{1}}{P_{2}}
$$

Here $\frac{\mathrm{MU}_{1}}{\mathrm{MU}_{2}}$ is the slope of the indifference curve and $\frac{\mathrm{P}_{1}}{\mathrm{P}_{2}}$ is the slope of the budget line.

Thus at equilibrium position, the above two slopes must be equal.

i.e., the budget constraint is tangent to the indifference curve.

The combination of goods at the point of tangency would give the optimum level of satisfaction to consumers.

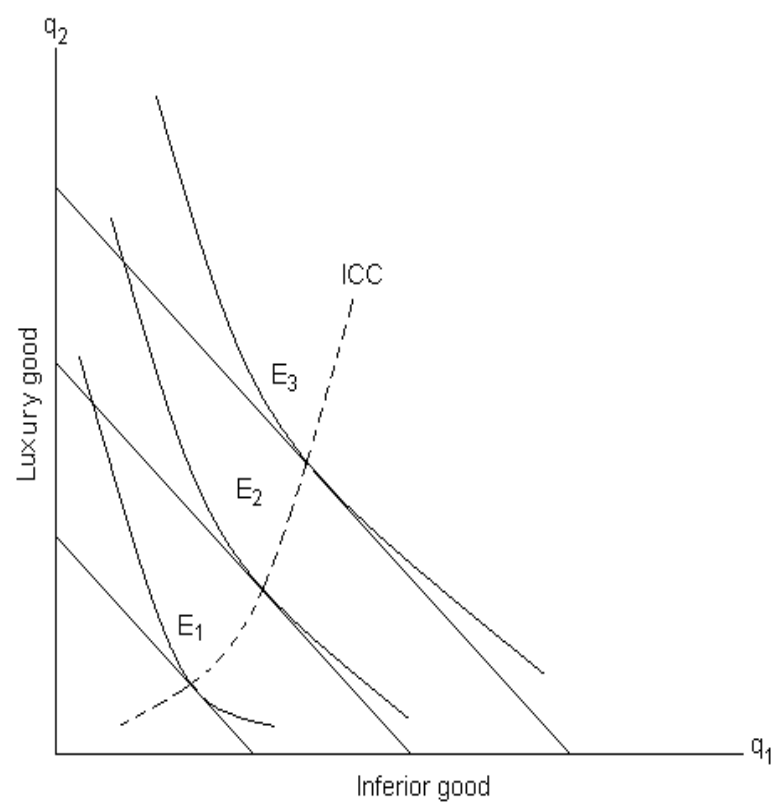

Fig. (i) Effects of income changes on consumer equilibrium (Price held constant)

Now we shift the budget line upward and for every shift get the equilibrium point on the indifference curve. The line formed by joining the equilibrium points on the indifference curve which we get by shifting the budget line up because of increase in income, other things being constant, is called the income-consumption curve (ICC). This is shown in Fig (i). This gives us how a consumer will consume the goods when his income rises.

The form of the ICC depends on consumer's behavior. If the ICC tilts towards a commodity axis then that commodity is treated as superior as compared to the other commodity. If it is negatively sloped, then both the commodities are normal goods. If it is negatively sloped, then one of the commodities is inferior. This is shown in Fig (ii). 


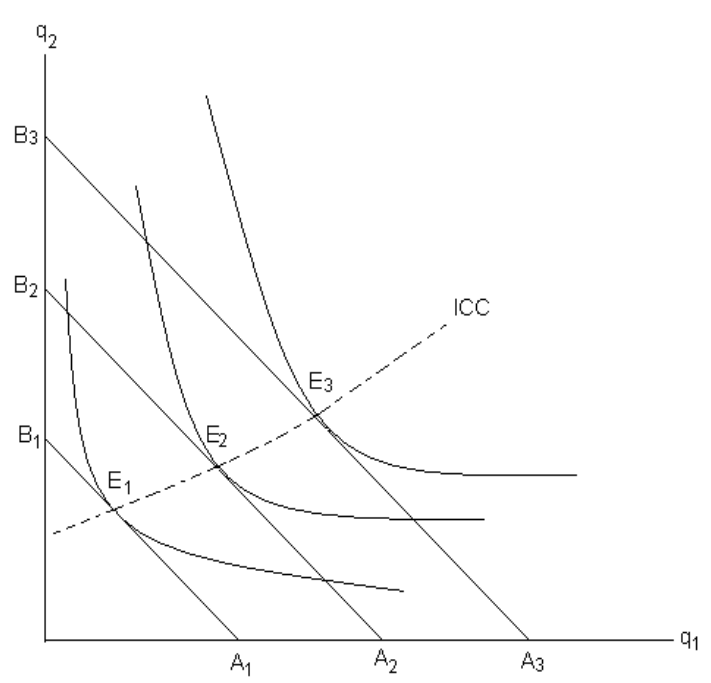

Fig. (ii): Downward sloping ICC

From the ICC we can draw the Engel curve. (An Engel curve is a relationship between quantity of a commodity say $\mathrm{Q}_{1}$ purchased and income of the consumer, prices being constant).

For inferior goods the Engel curve will be negatively sloped, for luxury goods it will be positively sloped and for necessities very small positive slope as shown below in Fig (iii).

In the set of equations (1) if we allow all the variables to vary simultaneously, we get on taking total differentiation with two variables.

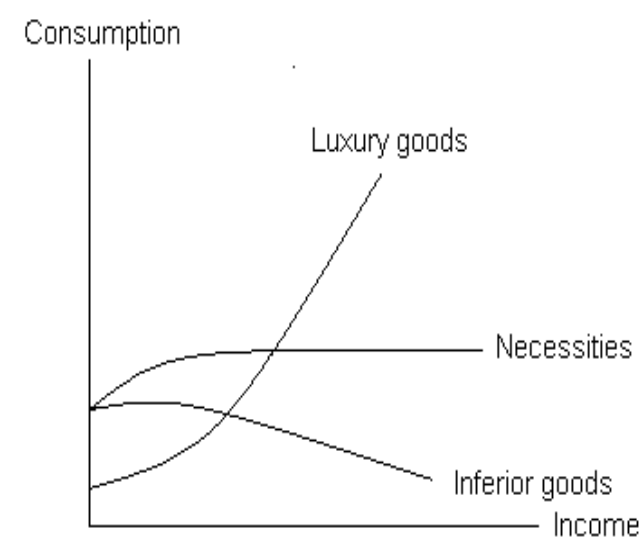

Fig. (iii) Engel Curve

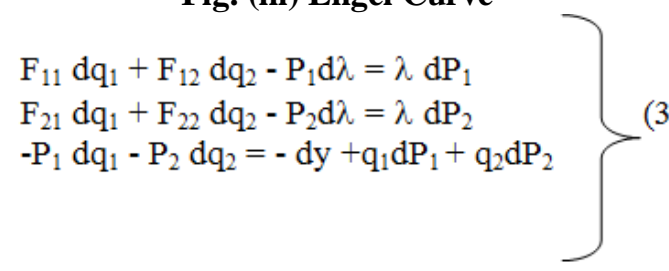

These are three equations in the three unknowns $\mathrm{dq}_{1}, \mathrm{dq}_{2}$ and $\mathrm{d} \lambda$ Solving (3) by using Crammer's Rule $\mathrm{dq}_{1}=\frac{-\lambda \mathrm{P}_{2}^{2} \mathrm{dP}_{1}+\mathrm{P}_{1} \mathrm{P}_{2} \lambda \mathrm{dP}_{2}+\left(-\mathrm{P}_{2} \mathrm{~F}_{12}+\mathrm{P}_{1} \mathrm{~F}_{22}\right)\left(-\mathrm{dy}+\mathrm{q}_{1} \mathrm{dP}_{1}+\mathrm{q}_{2} \mathrm{dP}_{2}\right)}{\mathrm{D}}$

Assuming only price $P_{1}$ changes and other things are constant,

i.e., $\mathrm{dP}_{2}=0$ and $\mathrm{dy}=0$,

(4) becomes

$$
\begin{gathered}
\frac{\partial q_{1}}{\partial P_{1}}=\frac{-\lambda P_{2}^{2}+\left(-P_{2} F_{12}+P_{1} F_{22}\right) q_{1}}{D} \\
=-\frac{\lambda P_{2}^{2}}{D}+\frac{q_{1}\left(-P_{2} F_{12}+P_{1} F_{22}\right)}{D}
\end{gathered}
$$

i.e. the rate of change of $q_{1}$ w.r. to $P_{1}$ when all others are kept constant is given by

$$
\frac{\partial q_{1}}{\partial P_{1}}=\frac{-\lambda P_{2}^{2}}{D}+\frac{q_{1}\left(-P_{2} F_{12}+P_{1} F_{22}\right)}{D}
$$

Similarly the rate of change of $\mathrm{q}_{1}$ w.r. to income $\mathrm{y}$ when others are kept constant is given by

$$
\frac{\partial \mathrm{q}_{1}}{\partial \mathrm{y}}=\frac{-\left(-\mathrm{P}_{2} \mathrm{~F}_{12}+\mathrm{P}_{1} \mathrm{~F}_{22}\right)}{\mathrm{D}}
$$

Consider price changes compensated by income changes leaving utility unchanged.

i.e., $\mathrm{dU}=0$

i.e., $F_{1} d_{1}+F_{2} d q_{2}=0$

$$
\text { i.e., } \frac{F_{1}}{F_{2}}=\frac{-d q_{2}}{d q_{1}}
$$

From equation (1)

$$
\frac{F_{1}}{F_{2}}=\frac{P_{1}}{P_{2}}
$$

Using (7) and (8)

$$
\frac{P_{1}}{P_{2}}=-\frac{d q_{2}}{d q_{1}}
$$

(ie) $\mathrm{P}_{1} \mathrm{dq}_{1}+\mathrm{P}_{2} \mathrm{dq}_{2}=0$

Then the last equation in (3) becomes

Substituting (9) in (4),

$$
-\mathrm{dy}+\mathrm{q}_{1} \mathrm{dP}_{1}+\mathrm{d}_{2} \mathrm{dq}_{2}=0 \text { (9) }
$$

$$
\left[\frac{\partial q_{1}}{\partial P_{1}}\right]_{U=\text { constant }}=-\frac{\lambda P_{2}^{2}}{D}
$$

From (5),(6) and (10) we get

$$
\frac{\partial q_{1}}{\partial P_{1}}=\left(\frac{\partial q_{1}}{\partial P_{1}}\right)_{U=\text { constant }}-q_{1}\left(\frac{\partial q_{1}}{\partial y}\right)_{\text {Prices=constant }}
$$

The above is called Slutsky equation

$$
\frac{\partial \mathrm{q}_{1}}{\partial \mathrm{P}_{1}} \text { gives the total effect when } \mathrm{P}_{1} \text { alone }
$$
changes.

$\mathrm{dq}_{1}=\frac{\lambda \mathrm{dP}_{1}\left(-\mathrm{P}_{2}^{2}\right)-\lambda \mathrm{dP}_{2}\left(-\mathrm{P}_{1} \mathrm{P}_{2}\right)+\left(-\mathrm{dy}+\mathrm{q}_{1} \mathrm{dP}_{1}+\mathrm{q}_{2} \mathrm{dP}_{2}\right)\left(-\mathrm{P}_{2} \mathrm{~F}_{12}+\mathrm{P}_{1} \mathrm{~F}_{22}\right.}{\mathrm{D}}\left(\frac{\partial \mathrm{q}_{1}}{\partial \mathrm{P}_{1}}\right)_{\mathrm{U}=\text { constant }}$

is called the substitution effect.

where

$$
\mathrm{D}=\left|\begin{array}{ccc}
\mathrm{F}_{11} & \mathrm{~F}_{12} & -\mathrm{P}_{1} \\
\mathrm{~F}_{21} & \mathrm{~F}_{22} & -\mathrm{P}_{2} \\
-\mathrm{P}_{1} & -\mathrm{P}_{2} & 0
\end{array}\right|
$$


$\mathrm{q}_{1}\left(\frac{\partial \mathrm{q}_{1}}{\partial \mathrm{dy}}\right)_{\text {price=constant }}$ is called the income effect.

Multiplying both sides of (11) by $\frac{\mathrm{P}_{1}}{\mathrm{q}_{1}}$ and multiplying the income effect on the R.H.S. by $\frac{y}{\bar{y}}$ we get

$\mathrm{E}_{11}=\mathrm{e}_{11}-\alpha_{1} \eta_{1}(12)$

$\mathrm{E}_{11} \quad$ is the price elasticity of the ordinary demand curve $\mathrm{e}_{11} \quad$ is the elasticity of compensated demand curve $\alpha_{1}$ is the proportion of the total expenditure spent on commodity $Q_{1}$ and $\eta_{1}$ is the income elasticity of demand for $\mathrm{Q}_{1}$

Equations (11) and (12) can be extended to account for changes in the demand for one commodity resulting from changes in the price of the other commodity.

The expression for this is

$$
\frac{\partial q_{i}}{\partial P_{i}}=\left(\frac{\partial q_{i}}{\partial P_{j}}\right)_{U=\text { constant }}-q_{j}\left(\frac{\partial q_{i}}{\partial y}\right)_{\text {price }=\text { constant }}
$$

and $\varepsilon_{\mathrm{ij}}=\mathrm{e}_{\mathrm{ij}}-\alpha_{\mathrm{j}} \eta_{\mathrm{i}}$ for $\mathrm{i}, \mathrm{j}=1,2$

if $\mathrm{i}=\mathrm{j}$ we get Slutsky's equations (11) and (12)

and if $i \neq j$ then

$$
\frac{\partial q_{i}}{\partial P_{j}} \text { or }\left(\frac{\partial q_{i}}{\partial P_{j}}\right)_{U=\text { constant }}
$$

will show the cross effects indicating the change in quantity demanded of $\mathbf{i}^{\text {th }}$ commodity when price of $\mathbf{j}^{\text {th }}$ commodity changes.

\section{DERIVATION OF ROY'S IDENTITY}

Consider Min $\mathrm{U}^{*}=\mathrm{F}^{*}\left(\mathrm{P}_{1}, \mathrm{P}_{2}, \ldots . . \mathrm{P}_{\mathrm{n}} \mathrm{y}\right)$

Subject to

The Lagrangian is $\mathrm{Z}=\mathrm{F}^{*}\left(\mathrm{P}_{1}, \mathrm{P}_{2}, \ldots \mathrm{P}_{\mathrm{n}} \mathrm{y}\right)+\mathrm{K}\left(\mathrm{y}-\mathrm{P}_{1} \mathrm{q}_{1}-\ldots\right.$. $\left.\mathrm{P}_{\mathrm{n}} \mathrm{q}_{\mathrm{n}}\right)$

Minimizing,

$$
\begin{gathered}
\frac{\partial \mathrm{F}^{*}}{\partial \mathrm{P}_{\mathrm{i}}}-\mathrm{Kq}_{\mathrm{i}}=0, \quad \mathrm{i}=1,2 \ldots \ldots \ldots \ldots . . . \mathrm{n} \\
\frac{\partial \mathrm{F}^{*}}{\partial \mathrm{y}}+\mathrm{K}=0 \\
\frac{\partial \mathrm{F}^{*}}{\partial \mathrm{K}}=\mathrm{y}-\mathrm{P}_{1} \mathrm{q}_{1}-\ldots \ldots \ldots . \mathrm{P}_{\mathrm{n}} \mathrm{q}_{\mathrm{n}}=0
\end{gathered}
$$

From the first set of $\mathrm{n}$ equations

$$
\frac{\frac{\partial F^{*}}{\partial P_{1}}}{q_{1}}=\frac{\frac{\partial F^{*}}{\partial P_{2}}}{q_{2}}=\ldots=\frac{\frac{\partial F^{*}}{\partial P_{n}}}{q_{n}}=K=\frac{-\partial F^{*}}{\partial y}
$$

or

$$
\begin{aligned}
& \frac{\frac{\partial U^{*}}{\partial P_{1}}}{q_{1}}=\frac{\frac{\partial U^{*}}{\partial P_{2}}}{q_{2}}=\ldots=\frac{\frac{\partial U^{*}}{\partial P_{n}}}{q_{n}}=K=\frac{-\partial U^{*}}{\partial y} \\
& \text { i.e. } q_{i}^{0}=-\frac{\frac{\partial U^{*}}{\partial P_{i}}}{\frac{\partial U^{*}}{\partial y}}, \quad i=1,2, \ldots \ldots \ldots . n
\end{aligned}
$$

This is 'Roy's Identity' which expresses the demand functions for the commodity in the consumption bundle of the consumer.

$$
\text { If } U^{*}=a_{1}\left(\frac{y}{P_{1}}\right)^{b_{1}}+a_{2}\left(\frac{y}{P_{2}}\right)^{b_{2}}
$$

Using Roy's identity

$$
\begin{aligned}
& q_{1}= \frac{-\left[-a_{1} b_{1} y^{b_{1}} p_{1}-b_{1}-1\right.}{a_{1} b_{1} y^{b_{1}-1} P_{1}-b_{1}+a_{2} b_{2} y^{b_{2}-1} P_{2}-b_{2}} \\
& q_{2}=\frac{-\left[-a_{2} b_{2} y^{b_{2}} P_{2}-b_{2}-1\right]}{a_{1} b_{1} y^{b_{1}-1} P_{1}-b_{1}+a_{2} b_{2} y^{b_{2}-1} P_{2}-b_{2}}
\end{aligned}
$$

Generally

$$
q_{i}=\frac{a_{i} b_{i} y_{i} b_{i} P_{i}^{-} b_{i}-1}{\sum_{j} a_{j} b_{j} y^{b_{j}-1} P_{j}^{-b_{j}}}, \quad i=1,2 \text { and } j=1,2
$$

\section{LINEAR EXPENDITURE SYSTEM (LES)}

In this a special type functional form is assumed for the utility function. This function satisfies the additive property.

i.e., Sum of different types of expenditure equals total expenditure and is homogeneous of degree one in income and prices.

i.e., $U$ is assumed to be

$U=\beta_{1} \log \left(q_{1}-\overline{q_{1}}\right)+\beta_{2} \log \left(\left(q_{2}-\overline{q_{2}}\right)+\ldots+\beta_{n} \log \left(q_{n}-\overline{q_{n}}\right)\right.$

where $\overline{q_{i}}$ is the quantity of $\mathrm{Q}_{i}$ commondity purchased and

$\mathbf{q}_{\mathbf{j}}$ is a

constant, $\mathrm{i}=1,2, \ldots . \mathrm{n}$

Maximizing this utility function subject to the budget constraint, we have

$\beta_{i}=\lambda p_{i}\left(q_{i}-\overline{q_{i}}\right) \quad i=1,2, \ldots n$

$\sum_{i=1}^{n} \beta_{i}=\lambda \sum_{i=1}^{n} p_{i}\left(q_{i}-\overline{q_{i}}\right)$

$\therefore \lambda=\frac{1}{\sum_{i=1}^{n} p_{i}\left(q_{i}-\bar{q}_{i}\right)}=\frac{1}{\left.\sum_{i=1}^{n} p_{i} q_{i}-\sum_{i=1}^{n} p_{i} \bar{q}_{i}\right)}$

Here

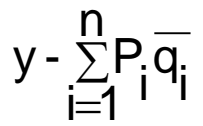

is defined as super-numerary income or uncommitted income and

$\beta_{i}$ are the marginal propensities to consume.

Published By:

Blue Eyes Intelligence Engineering 
(A) is interpreted as the expenditure $\left(\mathrm{P}_{\mathrm{i}} \mathrm{q}_{\mathrm{i}}\right)$ on a commodity at the optimum which is a sum of committed expenditures on that commodity $\left(\mathbf{P}_{\mathbf{i}} \overline{\mathbf{q}_{\mathbf{i}}}\right)$ and a portion $\left(\beta_{\mathrm{i}}\right)$ of the super-numerary income. The demand function derived in (B) can be written as

$$
x_{i h}=b_{i h}+\frac{a_{i}}{P_{i}}\left(\mu_{h}-\sum_{k=1}^{n} P_{k} b_{k h}\right) .
$$

Here $x_{i h}$ is the quantity and $P_{i}$ is the price of good $i$ and $\mu_{h}$ is the total expenditure of house hold $h$. The $b_{\text {ih }}$ here can be made as an explicit function of the characteristics of household such as age, education, occupation, number of members etc.

Let

$$
b_{i h}=\sum_{g=1}^{m} C_{i g} z_{g h}
$$

Where $C_{\text {ig }}$ is the effect of the $\mathrm{g}^{\text {th }}$ characteristic and $\mathbf{Z}_{\mathbf{g h}}$ is either a dummy variable or a quantitive variable.

The marginal budget shares $\left(\mathrm{a}_{\mathrm{i}}\right)$ can also be expressed as a function of household characteristics say

$$
a_{i h}=\sum_{g=1}^{m} a_{i g} z_{g h} \text { with } \quad \sum a_{i}=1
$$

\section{ALMOST IDEAL DEMAND SYSTEM (AIDS) \& RESULTS}

To derive the equation for AIDS, the structure of the cost function is essential. Consider a production process with two inputs say $X_{1}$ and $X_{2}$. Let $C^{0}$ be the amount of money, which a producer has for the expenditure on the two inputs. Let the input price be $\mathrm{P}_{1}$ and $\mathrm{P}_{2}$ for $\mathrm{X}_{1}$ and $\mathrm{X}_{2}$ respectively. If $\mathrm{X}_{1}$ and $\mathrm{X}_{2}$ are the quantities of the two inputs $X_{1}$ and $X_{2}$ then the cost line is given by $\mathrm{C}^{0}=\mathrm{P}_{1} \mathrm{x}_{1}+\mathrm{P}_{2} \mathrm{x}_{2}$.

This gives the locus of all combination of the two inputs which the producer can buy using his fixed outlay $\left(\mathrm{C}^{0}\right)$ at fixed input prices.

Let the production function is of the form

$$
y=A x_{1}^{a} x_{2}^{\beta}
$$

and the iso-cost line is

$\mathrm{C}=\mathrm{P}_{1} \mathrm{x}_{1}+\mathrm{P}_{2} \mathrm{x}_{2}+\mathrm{b}$ (general form $)$

Then

$$
\frac{\partial y}{\partial x_{1}}=\frac{\alpha A}{x_{1}}, \quad \frac{\partial y}{\partial x_{2}}=\frac{\beta A}{x_{2}}
$$

and the equilibrium condition is

$$
\frac{\frac{\partial y}{\partial x_{1}}}{\frac{\partial y}{\partial x_{2}}}=\frac{\alpha x_{2}}{\beta x_{1}}=\frac{P_{1}}{P_{2}}
$$

From the iso-cost equation

$\mathbf{P}_{1} \mathbf{x}_{1}=\mathrm{C}-\mathbf{P}_{2} \mathbf{x}_{2}-b$
Substituting in the expansion path

$$
\alpha x_{2} P_{2}-\beta\left(C-P_{2} x_{2}-b\right)=0
$$

$\therefore x_{2}=\frac{\beta}{\alpha+\beta}\left(\frac{c-b}{P_{2}}\right)$

$x_{1}=\frac{a}{a+\beta}\left(\frac{C-b}{P_{1}}\right)$

$\therefore y=A\left[\frac{\alpha}{\alpha+\beta}\left(\frac{C-b}{P_{1}}\right)\right]^{\alpha}\left[\frac{\beta}{\alpha+\beta}\left(\frac{c-b}{P_{2}}\right)\right]^{\beta}$

$\therefore y=A\left[\frac{\alpha}{\alpha+\beta}\left(\frac{C-b}{P_{1}}\right)\right]^{\alpha}\left[\frac{\beta}{\alpha+\beta}\left(\frac{c-b}{P_{2}}\right)\right]^{\beta}$

$\therefore y^{\frac{1}{\alpha+\beta}}=\left[\frac{A \alpha^{\alpha} \beta^{\beta}}{P_{1}^{\alpha} P_{2}^{\beta}}\right]^{\frac{1}{\alpha+\beta}} \cdot \frac{c-b}{\alpha+\beta}$

$\therefore C=(\alpha+\beta)\left(A \alpha^{\alpha} \beta^{\beta}\right)^{-\frac{1}{\alpha+\beta}} y^{\frac{1}{\alpha+\beta}} P_{1} \frac{\alpha}{\alpha+\beta} P_{2} \frac{\beta}{\alpha+\beta}+b$

$\alpha+\beta \quad$ is called the returns to scale, be denoted by $\mathrm{R}$. Then $C=R\left[A \alpha^{\alpha} \beta^{\beta}\right]-\frac{1}{R}{ }_{y}^{\frac{1}{R}} P_{1} \stackrel{\alpha}{R} P_{2} \stackrel{\beta}{R}+b$

i.e., $\mathrm{C}$ is of the form

$C=K y \stackrel{\frac{1}{R}}{P_{1}} \frac{\alpha}{R} P_{2} \frac{\beta}{R}+b$

Where

$K=R\left[A \alpha^{\alpha} \beta^{\beta}\right]^{-\frac{1}{R}}$

In the case of $\mathrm{n}$ inputs, it takes the form

$C=K y \frac{1}{R} P_{1} \frac{\alpha_{1}}{R} P_{2}^{\frac{\alpha_{2}}{R}} \ldots . . . P_{n} \frac{\alpha_{n}}{R}+b$

where $K=R\left[A \alpha_{1} \alpha_{1 \alpha_{2}} \alpha_{2} \ldots \ldots \alpha_{n} a_{n}\right]^{\frac{-1}{R}}$

and $\mathrm{R}=\alpha_{1}+\alpha_{2}+\ldots . .+\alpha_{\mathrm{n}}$

This cost structure is the basic for the assumption of AIDS

To derive the AIDS model, let the logarithm of the cost function for a given utility level $\mathrm{U}$ and price $\mathrm{P}$ be of the form

$\log C(U, P)=a_{0}+\sum_{k} a_{k} \log P_{k}+\frac{1}{2} \sum_{k} \sum_{j} g_{k j} \log P_{k} \log P_{j}+U B_{0} \Pi P_{k} B_{k}$

By definition $\frac{\partial C}{\partial P i}=q_{i}(U, P)=q_{i}$ (say)

Where $\mathrm{C}=\mathrm{C}(\mathrm{U}, \mathrm{P})$ 


$$
\begin{aligned}
& \text { i.e.. } \frac{\partial \mathrm{C}}{\partial \mathrm{P}_{\mathrm{i}}}=\mathrm{q}_{\mathrm{i}} \\
& \therefore \frac{\mathrm{P}_{\mathrm{i}}}{\mathrm{C}} \cdot \frac{\partial \mathrm{C}}{\partial \mathrm{P}_{\mathrm{i}}}=\frac{\mathrm{P}_{\mathrm{i}} \mathrm{q}_{\mathrm{i}}}{\mathrm{C}} \\
& \text { i.e., } \frac{\partial \log \mathrm{C}}{\partial \log \mathrm{P}_{\mathrm{i}}}=\frac{\mathrm{P}_{\mathrm{i}} \mathrm{q}_{\mathrm{i}}}{\mathrm{C}}=\mathrm{w}_{\mathrm{i}} \text { (say) }
\end{aligned}
$$

$\mathbf{w}_{\mathbf{i}}$ is the expenditure share of the $\mathbf{i}^{\text {th }}$ good

From (16)

$$
\begin{aligned}
& \frac{\partial \log C}{\partial \log P_{i}}=a_{i}+\sum_{j} g_{i j} \log P_{j}+U B_{0} B_{i}, \prod_{k} P_{k}^{B_{k}} \\
& \text { i.e.. } w_{i}=a_{i}+\sum_{j} g_{i j} \log P_{j}+U B_{0} B_{i} \prod_{k} P_{k}{ }_{k}
\end{aligned}
$$

Denote C(U.P) in (16) by Y. Then

$$
\begin{aligned}
& \log Y=a_{0}+\sum a_{k} \log P_{k}+\frac{1}{2} \sum_{k} \sum_{j} g_{k j} \log P_{k} \log P_{j}+U B_{0} \prod_{k} P_{k} B_{k} \\
& \therefore U B_{0} \prod_{k} P_{k} B_{k}=\log Y-\left[a_{0}+\sum_{k} a_{k} \log P_{k}+\frac{1}{2} \sum_{k} \sum_{j} g_{k j} \log P_{k} \log P_{j}\right]
\end{aligned}
$$

Substituting this in (17)

$$
w_{i}=a_{i}+\sum_{j} g_{i j} \log P_{j}+B_{i}\left[\log Y-\left(a_{0}+\sum a_{k} \log P_{k}+\frac{1}{2} \sum_{k} \sum_{j} g_{k j} \log P_{k} \log P_{j}\right)\right]
$$

Then the AIDS in the budget share form is

$$
w_{i}=a_{i}+\sum_{j} g_{i j} \log P_{j}+B_{i} \log \left(\frac{Y}{P}\right), \quad i=1,2, \ldots . n
$$

Where $\mathrm{P}$ is the price index defined in terms of individual prices given by

$$
\begin{array}{r}
\log P=a_{0}+\sum_{k} a_{k} \log P_{k}+\frac{1}{2} \sum_{k} \sum_{j} g_{k j} \log P_{k} \log P_{j} \\
g_{i j}=g_{j i}: \text { Symmetry condition }
\end{array}
$$

These conditions will ensure that the system satisfies the additivity, homogeneity in prices and income and the Slutsky symmetry conditions.
Here $a_{i}, B_{i}, g_{i j}$
$\mathrm{i}, \mathrm{j}=1,2 \ldots \ldots \mathrm{n}$ are parameters.

The non-linearity of these sets of equations requires the use of maximum likelihood methods of estimation.

For estimation purpose $\mathrm{P}$ is approximated to the price index given by $\log P=\sum_{k} w_{k} P_{k}$

where $w_{k}$ is the weight of $P_{k}$

In addition to the above, if the household size also is to be taken in the function, it is modified as

$$
w_{i}=a_{i}+\sum_{j} g_{i j} \log p_{j}+B_{1} \log \left(\frac{Y}{P}\right)+\theta_{i} \log S, \quad i=1,2 \ldots \ldots n
$$

The demand elasticities corresponding to the above AIDS are

(i) Own price elasticity $e_{i i}=\frac{g_{i i}-B_{i} w_{i}}{w_{i}}$
Cross price elasticity $e_{i j}=\frac{g_{i j}-B_{i} w_{j}}{w_{i}}$

Real expenditure elasticity $e_{i y}=\frac{B_{i}}{w_{i}}+\frac{g_{i i}-B_{i} w_{i}}{w_{i}}$

Household size elasticity $e_{i s}=\frac{\theta_{i}-B_{i}}{w_{i}}$

\section{REFERENCES}

1. Abdulai, A.,D.Jain and A.Sharma. 1999. "Household Food Demand Analysis in India." Journal of Agricultural Economics. 50: 316-327.

2. AbulWadud(2006) in his study on the meat demand in Bangaladesh using the Almost Ideal Demand System, The Empirical Economics Letters,5(1): (January 2006)

3. Barten, A.P., and C. Vanloot,1996. "Price Dynamics in Agriculture: An Exercise in Historical Econometrics." Economic Modelling. 13: 315-331.

4. Becker, G.S. 1965. "A Theory of Allocation of Time." Economics Journal. 75: 493-517.

5. Bhalla, G.S., P.Hazell and J.Kerr. 1999. "Prospect's for India's Cereal Supply And 6. Demand 2020." Food, Agriculture, and the Environment, Discussion Paper 29, International Food Policy and Research Institute.

6. Brahmananda,P. 1997. "50 years of Free Indian Economy," Indian Economic Association Trust for Research and Development, New Delhi, India.

7. Carpio,C. 2000, "Production Response of Cotton in India, Pakistan and Australia."M.S Thesis, Texas Tech University, Lubbock, Texas

8. Chalfant, J.A. (1987). 1987, "A Globally Flexible, Almost Ideal Demand System." Journal of Business and Economic Statistics. 5:233-242.

9. Chavas, J. and M.Holt. 1990. "Acreage Decision Under Risk: The Case of Corn and Soybeans." American Journal of Agricultural Economics. 72(3): 529-538.

10. "CIA - The World Factbook 2002 - India." Available on-line. http://www.odci.gov/cia/publications/factbook

11. Coyle, B.1989. "A Comment on the Specification of Linear Equations for Consumer Demand, output Supply and Factor Demand." Canadian Journal of Agricultural Economics. 37: 263-68.

12. Deaton, A. and J.Muellbauer. 1980a. "An Almost Ideal Demand System." The American Economic Review.70: 312-326

13. Deaton, A. and J.Muellbauer. 1980b. Economics and Consumer Behavior, Cambridge University Press, Cambridge.

14. Desai, G.M., and N.V. Namboodiri. 1983. "The Deceleration Hypothesis and Yield-Increasing Inputs in Indian Agriculture." Indian Journal of Agricultural Economics. 38:407-08.

15. Evenson, R., C.Pray, and M. Rosengrant. 1999. "Agricultural Research and Productivity Growth in India." International Food Policy Research and Productivity 16. Growth in India." International Food Policy Research Institute. Research Report 109.

16. Fang, C., S.Mohanty, \&J.Chaudhary. 2001. "Measuring Comparative Advantage of Indian Food Grains: A Policy Analysis Matrix Approach." Presented at the annual meeting of the /southern Agricultural Economic Association. 